\title{
Management of Post-Partum Uterine Prolapse in Malabari Goats
}

\author{
Sonu S. Nair1, Khan Sharun ${ }^{2} *$, R. Anuraj ${ }^{3}$ and Jacob Mathew ${ }^{4}$ \\ ${ }^{1}$ Division of Bacteriology and Mycology, ${ }^{2}$ Division of Surgery, ICAR-Indian Veterinary \\ Research Institute, Izatnagar, Bareilly, Uttar Pradesh, India \\ ${ }^{3}$ Emergency Veterinary Care, Vazhakkulam Block, Ernakulam, India \\ ${ }^{4}$ Veterinary Hospital, Nedumkandam, Idukki, Kerala, India \\ *Corresponding author
}

\author{
A B S T R A C T
}

\section{Keywords}

Post-partum;

Uterine prolapse;

Goat; Horizontal

mattress

Article Info

Accepted:

17 April 2019

Available Online:

10 May 2019
The purpose of the present paper is to describe the efficacy of horizontal mattress sutures in managing post-partum uterine prolapse in Malabari goats. Three cases of post-partum uterine prolapse were presented to Veterinary Hospital, Nedumkandam, Idukki, Keralawith the history of everted uterus hanging from the vagina. All of the cases were presented within 10 hours following the parturition. The prolapsed uterus was washed by using normal saline solution followed by washing with 1:1000 potassium permanganate solution. Sugar was applied topically to reduce the edema and there by the size of the prolapsed mass. Trans-vulval horizontal mattress retention sutures were applied using nylon after replacing the prolapsed uterus back into the pelvic cavity. Antibiotics, antiinflammatory, antihistaminic and vitamin supplements were provided. The sutures were removed on the $8^{\text {th }}$ day from the initial date of the presentation. All the animals made an uneventful recovery.

\section{Introduction}

Uterine prolapse is defined as the complete post-partum eversion of the gravid horn (Noakes et al., 2009). It is a common postpartum complication mostly reported in cattle and sheep but comparatively less in goat (Sahadev et al., 2014). Uterine prolapse occurs mostly within a few hours after parturition when the cervix is open and the uterus lacks tone (Hanie, 2006). Several factors are responsible for uterine prolapse but in most cases, identification of the responsible factors is difficult (Jackson, 2004).

The outcome of uterine prolapse following the treatment depends on several factors which varies for each case but mainly depends on time of presentation, degree of damage and contamination (Wachida and Kisani, 2011). Several complications are reported secondary to uterine prolapse. Some of them are haemorrhage, shock, septic metritis, low milk yield, infertility or death. Sometimes in delayed cases of uterine 
prolapse, partial contraction of the cervix interferes with repositioning the prolapsed mass (Gyan et al., 2011). Following the replacement of prolapsed uterus, broad spectrum antibiotic therapy for three to five days will help in preventing secondary bacterial infection (Borobia-Belsué, 2006).

The present paper describes the successful management of post-partum uterine prolapse in Malabari breed goat presented to Veterinary Hospital, Nedumkandam, Idukki, Kerala.

\section{Case history and clinical examination}

A total of three cases of post-partum uterine prolapse was presented to Veterinary Hospital, Nedumkandam, Idukki, Kerala. The animals were standing with the everted uterus hanging from the vagina. Fetal membranes were found to be attached to the uterine caruncles. Further details of the cases are given in Table 1. All of the cases were presented within 10 hours following the parturition. The presented animals belonged to different age groups with different parity without any pattern of occurrence.

\section{Treatment}

The treatment was initiated by giving Dextrose Normal Saline (DNS) solution and Calcium gluconate intravenously. The adhered fetal membranes were removed by carefully separating the caruncles from the cotyledons. The prolapsed uterus was washed by using normal saline solution followed by washing with 1:1000 potassium permanganate solution $\left(\mathrm{KMnO}_{4}\right)$ for removing all the debris. Application of sugar crystals to the prolapsed and edematous uterine mass was effective in reducing the size of the uterus which enabled it to be replaced into the pelvic cavity without any unnecessary force (Figure 1). The animal was kept in standing position and the prolapsed uterine mass was replaced into the pelvic cavity by gentle handling and manipulations so that hemorrhage secondary to uterine tear is prevented. After replacing the prolapsed uterus back into pelvic cavitytrans-vulval horizontal mattress retention sutures were applied using nylon. This will further prevent the possibility of recurrence. Antibiotics, anti-inflammatory, antihistaminic and vitamin supplements were provided. A dose of tetanus toxoid was given as a preventive measure. Oral supplementation of calcium and phosphorus containing mineral mixture was given for a period of one month. No epidural anesthesia and oxytocin was given in any of the cases. But advised the owner to strip off excess milk to stimulate the natural release of oxytocin.

\section{Results and Discussion}

The sutures were removed on the $8^{\text {th }}$ day from the initial date of the presentation. A gradual increase in milk production was noticed and all of the animals recovered uneventfully.

One of the most common complications associated with uterine prolapse is toxemia which occurs mostly due to fecal contamination of the prolapsed uterus (Bharti and Rajnish, 2014). Proper management of uterine prolapse is important since it will enable the animal to be conceived again without any complication (Pothiappan et al., 2013). If the prolapsed uterus is subjected to trauma due to delayed management there might be a possibility of uterine adhesions. Adhesions of the uterus to the abdominal cavity will cause dystocia in the subsequent pregnancy due to insufficient expulsion force. Such cases have to be surgically managed (Khan et al., 2018). Cleaning of the prolapsed uterine mass using normal saline or mild antiseptic solution is necessary to prevent the contamination but aggressive attempts to remove superficial contamination should be 
avoided since it may cause the absorption of toxic contaminants into the systemic circulation (Scott and Gessert, 1998).

Uterine prolapse will produce interference in the blood supply of prolapsed mass. This will produce time dependent changes that progress from edema, cyanosis and later it can even develop into gangrene (Kapadiya et al., 2015). Hence, the duration of prolapse is one of the critical factors that decides the success while managing the prolapsed uterus.
Among the three cases of post-partum uterine prolapse included in the study, all of the prolepses occurred within a time period of 10 hours after kidding. This indicates that the post-partum prolapse of the uterus occurs commonly within hours after parturition in Malabari goats. Uterine prolapse in goats is not as complicated as in case of large ruminants. The comparatively smaller size of the uterus when compared to cattle, makes it easy for correction in goats. Use of epidural anaesthesia is not necessary if straining is absent (Fig. 2).

Table.1 Clinical examination findings of Malabari goat presented with post-partum uterine prolapse

\begin{tabular}{|c|c|c|c|c|c|c|}
\hline Case & Age & Parity & $\begin{array}{c}\text { Body } \\
\text { temperature }\end{array}$ & Pulse & $\begin{array}{c}\text { Respiratory } \\
\text { rate }\end{array}$ & $\begin{array}{c}\text { Time of } \\
\text { presentation }\end{array}$ \\
\hline Case 1 & 3 year & 2 & $102.4^{\circ} \mathrm{F}$ & $79 / \mathrm{min}$ & $19 / \mathrm{min}$ & 5 hour \\
\hline Case 2 & 2 year & 1 & $102.7^{\circ} \mathrm{F}$ & $82 / \mathrm{min}$ & $17 / \mathrm{min}$ & 8 hour \\
\hline Case 3 & 5 year & 4 & $102.3^{\circ} \mathrm{F}$ & $82 / \mathrm{min}$ & $16 / \mathrm{min}$ & 10 hour \\
\hline
\end{tabular}

Fig.1 Application of sugar crystals to reduce the size of the prolapsed uterine mass. Left - Before topical application of sugar. Right - Considerable decrease in the size of the prolapsed mass
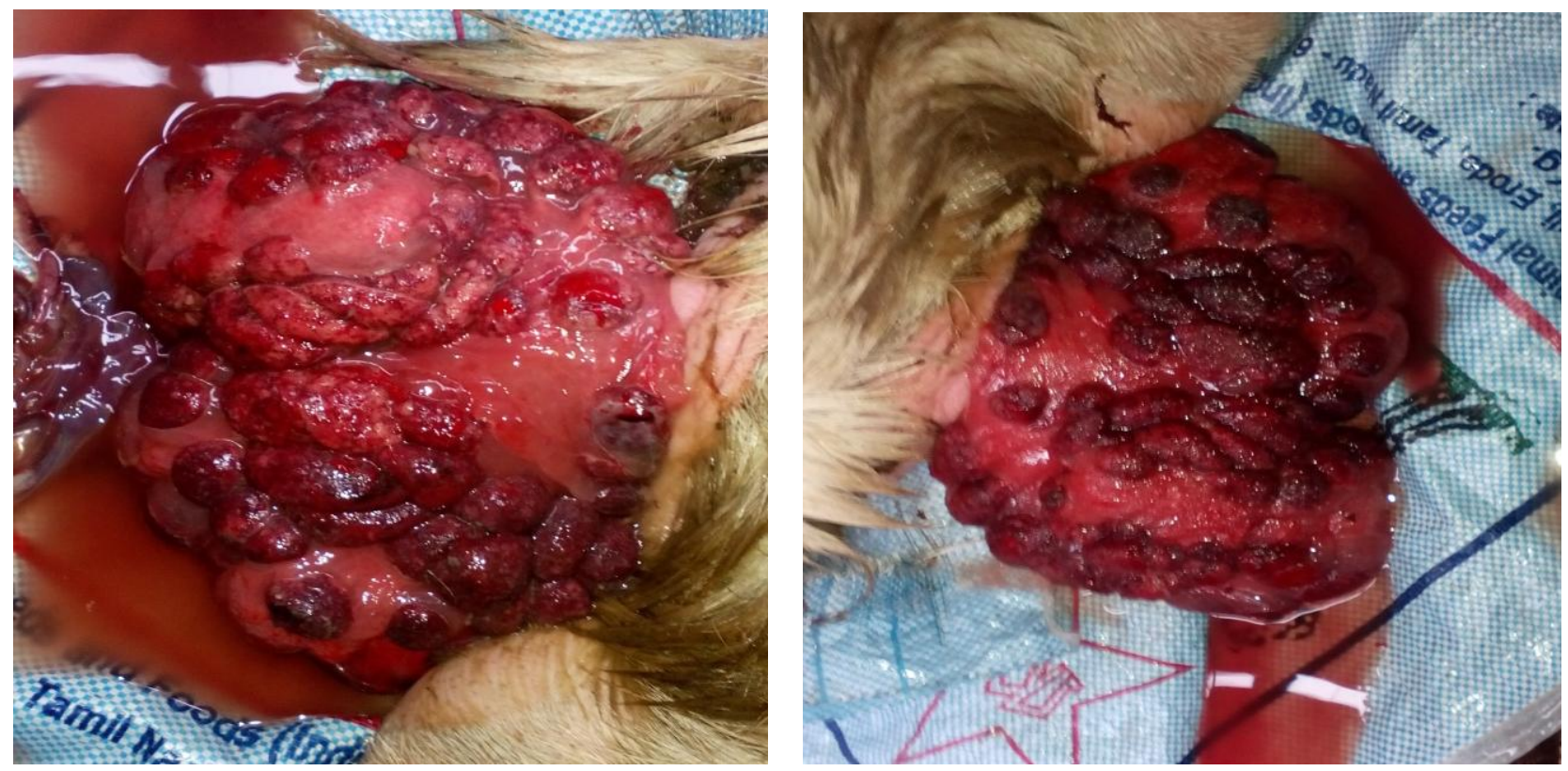
Fig.2 (Left) -The three cases of postpartum uterine prolapse in Malabari goats before the correction. Maternal caruncles are visible externally.

(Right) - The animals following the application of horizontal mattress suture after replacement of prolapsed uterus
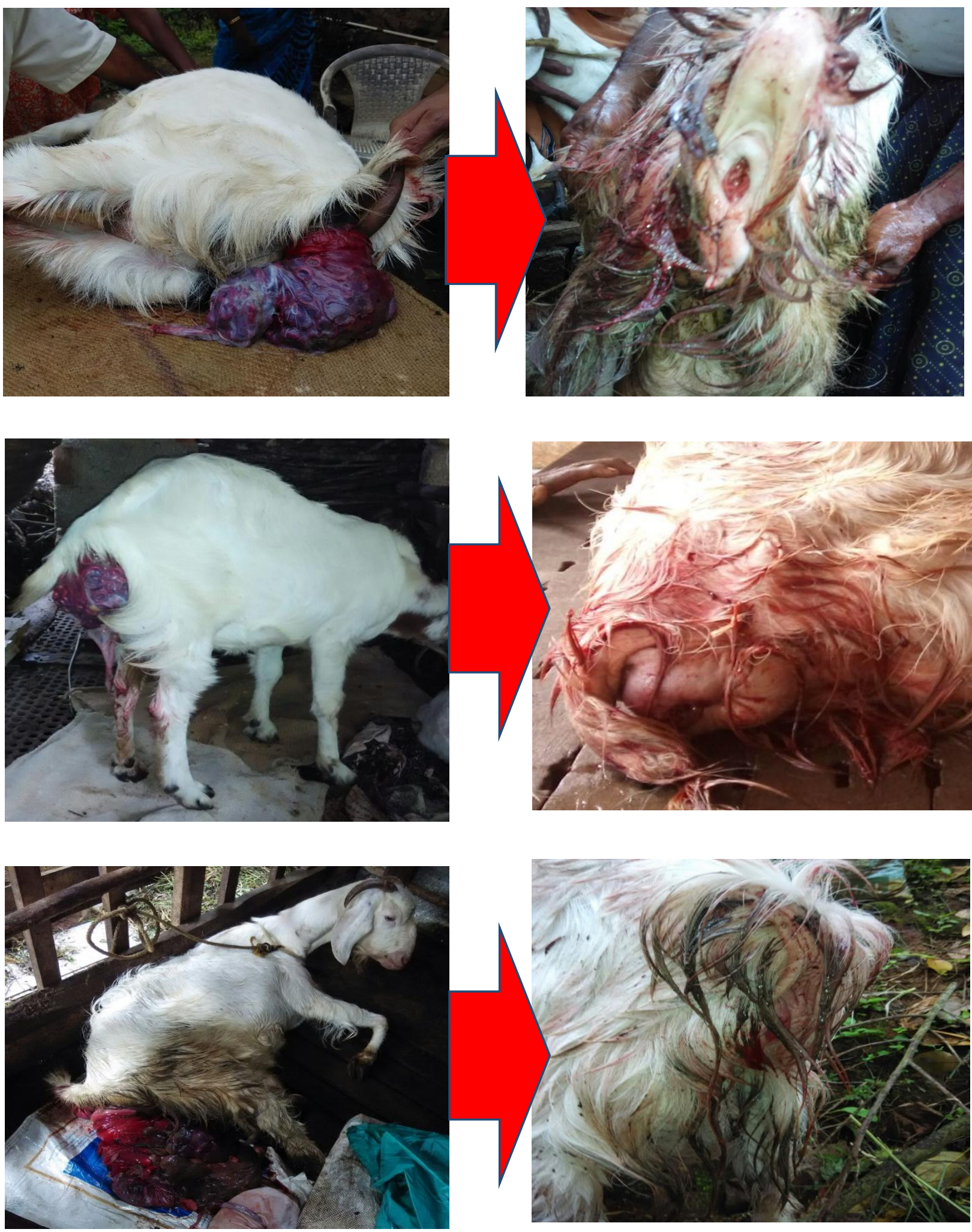
Secondary complications like trauma, septicemia, and hemorrhage are also found to be of less incidence in goats. Managemental corrections are very, much essential to prevent a recurrence. The future fertility of goats is not affected unless there is not much injury or lacerations or gangrenous changes in the uterus.

\section{References}

Bharti, K. and Rajnish, S., 2014. Management of uterine prolapse in goat-a case report. International Journal of Livestock Research, 4(8), pp.27-29.

Borobia-Belsué, J., 2006. Replacement of rectal prolapse in sows Veterinary Record 158, pp. 380.

Gyan, S., Pandey, A.K., Rajesh, K. and Sandeep, K., 2011. Post-parturient uterine prolapse in a goat-a case report. Veterinary Practitioner, 12(2), 192-193.

Hanie, E.A., 2006. Prolapse of the Vaginal and Uterus: Text Book of Large Animal Clinical Procedures for Veterinary Technicians. Elsevier, Mosby, pp: 218-221.

Jackson, P.G.G., 2004. Postparturient Problems in Large Animals. Handbook of Veterinary Obstetrics. pp. 209- 231.

Kapadiya, P.S., Chauhan, P.M., Nakhashi, H.C., Sharma, V.K. and Sutaria, T.V.,
2015. Recurrent post-partum uterine prolapse in a primiparous Mehsana buffalo-A case report. Journal of Livestock Science, 6, pp.109-112.

Khan, S., Satheesh, A., Sabarinadh, V.R., Ranjith Mohan, M., Sidhique, S.A. and Panikkassery, S., 2018. Surgical management of dystocia due to uterine adhesion in a goat. 6(6): 988-991.

Noakes, D.E., Parkinson, T.J. and England, G.C.W., $2009 . \quad$ Veterinary Reproduction and Obstetrics. Saunders. p. 322-33.

Pothiappan, P., Sureshkumar, R., Vijay Kumar, H. and Dhanan Jaya Rao, G., 2013. Postpartum uterine prolapse in a non-descript doe and its management. Indian Veterinary Journal, 90: 66-67.

Sahadev, A., Suchitra, B.R. and Renukaradhya, G.J., 2014. Management of Postpartum Uterine Eversion in a Ewe. Intas Polivet, 15(2): 448-449.

Scott, P. and Gessert, M., 1998. Management of ovine vaginal prolapse. In Practice, 20(1), pp.28-34.

Wachida, N. and Kisani, A.I., 2011. Uterine prolapse in a doe goat: A case report. International Journal of Animal and Veterinary Advances, 3(3): pp.135137.

\section{How to cite this article:}

Sonu S. Nair, Khan Sharun, R. Anuraj and Jacob Mathew. 2019. Management of Post-Partum Uterine Prolapse in Malabari Goats. Int.J.Curr.Microbiol.App.Sci. 8(05): 2136-2140. doi: https://doi.org/10.20546/ijcmas.2019.805.250 